\title{
Guías de turismo y patrimonio histórico
}

Joaquín Pérez Ordóñez | Guía oficial de turismo de Andalucía; licenciado en geografía e historia

URL de la contribución <www.iaph.es/revistaph/index.php/revistaph/article/view/3489>

\section{En general}

No cabe duda de que la formación en historia del arte proporciona una buena base para el ejercicio de la profesión de guía de turismo. Pero es importante añadir que dicha profesión es mucho más compleja de lo que se suele pensar desde fuera, y que requiere conocimientos y competencias que van más allá del mero conocimiento del patrimonio histórico-artístico. Entre otros citaré:

- geografía física y humana (las últimas promociones de licenciados y grados no necesariamente cuentan con dicha formación en sus itinerarios curriculares, a diferencia de planes más antiguos);

- materias específicas de turismo y hostelería;

- botánica y, en menor medida, agricultura;

- vocalización y técnicas de oratoria (quienes hayan pasado por el CAP posiblemente las tengan, pero no todos los historiadores del arte necesariamente cuentan con este certificado de aptitud pedagógica);

- dinámica de grupos;

- idiomas: son muy importantes, más aún en un contexto de crisis e hundimiento del turismo nacional y crecimiento del turismo foráneo, el dominio de idiomas (según la legislación vigente en Andalucía, al menos dos, además del español). A este respecto añadiré que no bastan unos conocimientos medios, sino que estas competencias de manejo de idiomas deben ser muy fluidas. No basta un nivel B1 o B2, como mínimo debe ser C1 y, aún así, son pocos los guías que tienen una carga de trabajo razonable sin contar, como mínimo, con un nivel C2.

Tal vez por desconocimiento, y por una visión que reduce el interés del turista al ámbito del patrimonio estricta- mente histórico-artístico, se pensaría que un licenciado o grado en historia del arte sale preparado para ejercer la profesión de guía de turismo. El interés de los turistas no se limita a ese patrimonio, existen otros: patrimonio natural, industrial, sociológico, etc.

Plantearé una situación bastante común a modo de ejemplo: las visitas a los Reales Alcázares de Sevilla o a la Alhambra de Granada incluyen casi siempre los jardines de ambos monumentos. ¿Estaría preparado un historiador del arte para responder a preguntas acerca del nombre de árboles y arbustos, épocas de floración, usos de los mismos, etc.? Por no mencionar el hecho de que no bastaría con hacerlo en español, sino también en otros idiomas.

No estamos hablando de situaciones extrañas, sino de la cotidianidad del desempeño profesional del guía, y téngase en cuenta que he citado los dos monumentos más visitados de Andalucía (junto a la Catedral de Sevilla y la Mezquita de Córdoba).

Se podría aducir que un historiador del arte podría formarse a posteriori en cada uno de los campos mencionados más arriba. Pero, igualmente, cualquier profesional proveniente de esos ámbitos tendría derecho a argumentar que también podría formarse después en historia del arte.

\section{Falsos mitos}

Por otro lado me gustaría desmentir algunos mitos bastante extendidos acerca de la profesión de guía de turismo:

- Los guías de turismo no están formados o carecen de titulación: falso

Si bien es cierto que hace muchos años (tantos que sería difícil encontrar guías en activo de esa época) la 
profesión no estaba muy reglamentada y había guías con escasa formación académica, la realidad es que, según la legislación vigente, para acceder a la profesión, y como requisito previo a la participación en los exámenes, se exige una titulación universitaria de al menos tres años (las antiguas diplomaturas y, como excepción, los técnicos superiores en turismo).

De hecho, en cierta ocasión la Administración decidió realizar unas pruebas de acceso en las que, con carácter extraordinario, no se exigía tal requisito, y todas las asociaciones de guías manifestaron su oposición y recurrieron tal convocatoria ante los tribunales.

Así mismo, cada vez que la Administración lo estima oportuno los guías deben pasar por pruebas y cursos de reciclaje. Pero como no se trata de obligación, sino de vocación, los propios guías como colectivo organizan con bastante frecuencia y regularidad cursos y seminarios dentro de los más diversos ámbitos para mantener sus competencias al día.

- Los guías de turismo limitan el acceso a la profesión: falso

Para bien o para mal, es algo que no depende en absoluto de los guías, ni individual ni colectivamente, sino de la Administración. Si bien es cierto que hacia finales de los años 90 del pasado siglo había un número de guías que se llegó a considerar excesivo, y las diferentes asociaciones manifestaron, como una mera opinión, la conveniencia de no convocar más exámenes, hoy en día la inmensa mayoría del colectivo coincide en la necesidad de convocar exámenes, sobre todo teniendo en cuenta que hace ya años que no se hace.

Sin embargo, como ya se ha mencionado, depende exclusivamente de la Administración. En estos momentos se está discutiendo una nueva legislación al respecto y parece poco probable que se convoquen exámenes antes de que todos los trámites hayan concluido.

Hay opiniones extendidas, dentro de la Administración y ciertos sindicatos, favorables a rebajar los criterios de exigencia para el acceso a la profesión, algo a lo que se oponen los guías con total firmeza y, por qué no decirlo, escaso éxito.

Atención, esto no supone ninguna buena noticia para los historiadores del arte. De lo que se trata es de que los titulados de formación profesional puedan acceder a la profesión. Se podrá discutir si esto es deseable o no pero, desde luego, no ayudará a los historiadores del arte a acceder a la profesión (ni a los guías a ejercerla).

- Los guía impiden que otros profesionales expliquen el patrimonio: sí y no

Es absolutamente falso, por ejemplo, que los guías de turismo interfieran en las visitas de carácter académico. De ello pueden dar fe los gestores de cualquier monumento. Lo que molesta a los guías es que visitas puramente turísticas, y cuya competencia la legislación reserva a los guías, sean realizadas por personas ajenas a la profesión.

\section{Conclusión}

El ámbito de competencia de los guías de turismo son los BIC, particularmente los de titularidad pública.

Dada la especial naturaleza de los mismos, parece necesario que dicha profesión esté reglamentada y controlada por la Administración.

Podríamos poner como ejemplo ilustrativo y comparativo el acceso a la enseñanza pública: no basta con ser historiador del arte, por ejemplo, para ejercerla: además hay que haber realizado el CAP y aprobar unas oposiciones. 
a debate Historiadores del arte ¿para qué? Una titulación en busca de una profesión | coordina José Castillo Ruiz

Se podría objetar que tales requisitos no son obligatorios en la enseñanza privada, pero la comparación sigue siendo igualmente pertinente: los monumentos de titularidad privada disponen a menudo de guías que no son guías oficiales (plaza de toros de la Real Maestranza, palacio de la Condesa de Lebrija, planta alta de la Casa de Pilatos, y un largo etcétera); nada impide a un historiador del arte enviar a tales monumentos su currículum vítae y, con fortuna, ser empleado por los mismos.

Dada la multidisciplinariedad por antonomasia de la profesión de guía de turismo, parece razonable implantar pruebas de acceso, cursos, o cualquier otros sistema de control que garantice las competencias necesarias para el ejercicio de la misma.

No parece razonable, por el contrario, oponerse a la exclusividad de los guías de turismo para el ejercicio de su profesión, para reclamar dicha exclusividad en beneficio de otro colectivo, sea el de los historiadores del arte o de cualquier otro, más aún cuando se trata de una profesión multidisciplinar (es preciso reiterarlo y subrayarlo) cuyas competencias desbordan ampliamente las propias de la mera gestión e interpretación del patrimonio histórico-artístico. 